\title{
COVID-19 COMO DOENÇA OCUPACIONAL: UMA ANÁLISE SOBRE AS DIFERENTES POSIÇÕES ADOTADAS ENTRE O PODER EXECUTIVO E O JUDICIÁRIO NA PANDEMIA DO CORONAVÍRUS
}

\author{
COVID-19 AS OCCUPATIONAL DISEASE: AN ANALYSIS ON THE \\ DIFFERENT POSITIONS ADOPTED BETWEEN EXECUTIVE AND \\ JUDICIAL POWER IN THE CORONAVIRUS PANDEMIC
}

Guilherme Sebalhos Ritzel ${ }^{1}$

\begin{abstract}
RESUMO
Este trabalho tem por finalidade abordar a doença ocupacional no direito brasileiro, e mais precisamente, sob a ótica da pandemia da Covid-19 (desencadeada pelo coronavírus). Trata-se de uma situação peculiar, responsável por uma crise sanitária de consequências globais e inimagináveis até recentemente. Foi utilizado o método dedutivo para este trabalho, tendo em vista as diferentes visões sobre o tema. Por exemplo, o Poder Executivo e o Poder Judiciário tiveram decisões antagônicas sobre o assunto (como no artigo 29 da MP 927, vetado pelo Supremo Tribunal Federal). Logo, entende-se que este tipo de situação causa insegurança jurídica para todas as partes envolvidas (para empregadores, para o INSS e os seus segurados), sendo especialmente prejudicial para os trabalhadores nestes tempos de pandemia. Da mesma forma, não se percebeu argumentos claros que fundamentem a impossibilidade da Covid-19 ser caso de doença ocupacional.
\end{abstract}

Palavras-chave: Covid-19; Doença Ocupacional; Pandemia.

\begin{abstract}
This work aims to address occupational disease in Brazilian law, and more precisely, from the perspective of the Covid-19 pandemic (triggered by the coronavirus). It is a peculiar situation, responsible for a health crisis with global and unimaginable consequences until recently. The deductive method was used for this work, considering the different views on the subject. For instance, the Executive Branch and the Judiciary had antagonistic decisions on the subject (as in Article 29 of MP 927, vetoed by the Supreme Federal Court, for example). Therefore, it is understood that this type of situation causes legal uncertainty for all parties involved (for employers, for the INSS and their insured persons), being especially harmful to workers in these pandemic times. Likewise, no clear arguments were found to support Covid-19's impossibility of being na occupational desease.
\end{abstract}

Keywords: Covid-19; Occupational disease; Pandemic.

\footnotetext{
${ }^{2}$ Graduado em Direito pelo Centro Universitário Franciscano (UNIFRA). especialista em Direito do Trabalho pela Universidade Franciscana (UFN), graduando em Ciências Sociais pela Universidade Federal de Santa Maria (UFSM) e advogado (OAB/RS 114.815). E-mail: guilherme.sebalhos@acad.ufsm.br
} 


\section{INTRODUÇÃO}

A pandemia desencadeada pelo vírus da Covid-19 trouxe uma crise global, tanto no ponto de vista sanitário como econômico. Tendo em vista esta situação, muitos trabalhadores estiveram em situação bastante peculiar, enquanto alguns mudaram sua prestação de serviço por meio do teletrabalho, para a grande maioria das profissões este recurso não é viável, sendo a locomoção ao trabalho uma forma de deixar as pessoas expostas ao vírus.

Com isso, este trabalho defende a posição de que há possibilidade de se relacionar a Covid-19 com o ambiente de trabalho (sendo equivocada a ideia de desconsiderar essa possibilidade previamente). Isto é, em muitas situações se evidencia a relação entre a contaminação e o ambiente de trabalho, seja em casos de elevado número de funcionários da empresa adoecidos, seja em outras questões (como aglomerações no estabelecimento ou relaxamento nos cuidados).

Diante desta situação, utilizou-se o método dedutivo, baseando-se nas diferentes posições entre o Poder Judiciário e o Poder Executivo nacional. No primeiro capítulo foi conceituada a previdência social, exposta a sua importância em infortúnios da vida do segurado (como em caso de doença), no capítulo seguinte foi feita a distinção entre o auxílio-doença comum e o acidentário, e no último, se discorreu a respeito das diferentes posições entre os Poderes (executivo e judiciário) a respeito da Covid-19 como doença ocupacional.

Após algumas atitudes do Poder Executivo brasileiro em tentar descaracterizar a Covid-19 como doença ocupacional (como a MP 927/2020 no artigo 29), o Poder Judiciário foi invocado para manifestação e decidiu de maneira contrária. Acredita-se que a disparidade de entendimentos sobre o tema cria insegurança jurídica para todas as partes envolvidas, para o Estado por meio do INSS, para os empregadores, e principalmente para os trabalhadores. Diante de uma crise pandêmica, prejudicial para a saúde de todos, é de suma importância resguardar o sistema de proteção social.

Portanto, afirma-se a necessidade de discutir o assunto, pois as medidas adotadas pelo Poder Executivo que concluíram não ser caso de doença ocupacional a contaminação do vírus da Covid-19 foram equivocadas. Logo, há que se lembrar que o aumento do risco de contaminação para a sociedade deve ser observado sob a ótica do direito à saúde do trabalhador (artigo $6^{\circ}$ e 196 da Constituição Federal).

\section{CONSIDERAÇÕES SOBRE A PREVIDÊNCIA SOCIAL.}

A previdência social surgiu como maneira de organizar a sociedade por meio de um sistema contributivo, sendo uma forma de o Estado assegurar para os indivíduos uma contraprestação pecuniária diante das adversidades da vida. Logo, há de se ressaltar que a previdência social visa a propiciar meios de provimento às necessidades básicas das pessoas. 
Conforme expressa Wladimir Novaes Martinez (1992, p. 99), a previdência social pode ser conceituada da seguinte forma:

[...] a técnica de proteção social que visa propiciar os meios indispensáveis à subsistência da pessoa humana - quando esta não pode obtê-los ou não é socialmente desejável que os aufira pessoalmente através do trabalho, por motivo de maternidade, nascimento, incapacidade, invalidez, desemprego, prisão, idade avançada, tempo de serviço ou morte.

Lazzari e Castro (2018, p. 9) explicam que a importância da previdência social nasce do seguinte fato: De maneira geral, os indivíduos têm na força de trabalho sua única forma de sustento:

O indivíduo - assalariado ou não - na maioria das vezes tem como única fonte de recursos ele próprio; é ele sua força de trabalho. Com a perda ou a redução, definitiva ou temporária, de sua capacidade laborativa, sem as políticas de atuação estatal na esfera da Previdência, mediante a manutenção de um seguro social, é levado, junto com seus dependentes, à miséria, tendo de recorrer à caridade, caso não tenha sido precavido ou tenha tido condições de poupar economias para um futuro incerto. A Previdência Social surge primordialmente da preocupação com o sustento dos que, tendo sido trabalhadores, encontram-se fora do mercado de trabalho por falta de condições físicas ou mentais.

Do ponto de vista histórico, empregados e empregadores passaram a contribuir para um fundo comum destinado ao amparo e a proteção contra os infortúnios do mundo do trabalho desde o fim do século XIX, com o pioneirismo da Alemanha de Otto von Bismark (FAGNANI, 2019, p. 20). Há também de se ressaltar a mudança de diretriz econômica do Século XX, como se observa no modelo norte-americano do "New Deal" e a adoção do "Social Security Act" em 1935, e em linha próxima, o sistema previdenciário britânico conhecido por meio do "Relatório Beveridge" de 1942 (FAGNANI, 2019, p. 20).

Entende-se que o marco inicial da previdência social foi uma resposta para a insatisfação social em face da precariedade do trabalho no século XIX, já o seu impulsionamento se sucedeu com a crise econômica após 1929. Kertzman (2019, p. 49) aborda que o New Deal norte-americano foi inspirado no "Welfare State" (Estado de bem-estar social), que visava regular a economia, fortalecendo a saúde pública, a assistência social e a previdência social).

Wladimir Novaes Martinez (2015, p. 36) contextualiza como marco formal para a previdência social no Brasil a Lei Eloy Chaves de 1923 (complementada pelo Decreto Legislativo 5.106/1926), tendo em vista o objetivo de assegurar benefícios para ferroviários. Explica o autor que este instituto autorizava as chamadas "Caixas de aposentadoria e pensão" para a categoria de trabalhadores ferroviários em todo país.

Por meio da Lei Eloy Chaves, os trabalhadores ferroviários passaram a gozar de benefícios como aposentadoria ordinária, aposentadoria por invalidez, pensão por morte, assim como assistência médica. Tal situação foi possível por meio de uma contribuição mensal de 3\% dos trabalhadores e outra patronal concedida anualmente de 1\% sobre a renda bruta da empresa (MARTINEZ, 2015, p. 36). 
Já na década de 1930, o governo brasileiro tomou como modelo o sistema de contribuição entre empregados e empregadores, só que englobando a participação do Estado, conforme a criação dos IAP's (Institutos de Aposentadoria e Pensão). Em consequência da criação dos Institutos de Aposentadoria e Pensão, surgiu a base para o INPS (Instituto Nacional de Previdência Social) na década de 1960 (MARTINEZ, 2015, p. 15). Com esta perspectiva histórica, após a promulgação da Constituição de 1988, a previdência social se torna parte do sistema de seguridade social em conjunto com a saúde e a assistência social, prevista no artigo 194 da Constituição Federal.

Desta forma, surgiu o INSS (Instituto Nacional do Seguro Social) em 1990, tendo como base a Lei 8212/91 que dispõe sobre o financiamento da Seguridade Social e a Lei 8213/91 que dispõe sobre os benefícios previdenciários e seus beneficiários. Dentre os benefícios elencados pela legislação previdenciária se encontram o auxílio-doença (artigo 59, podendo ser comum ou acidentário) e o auxílio-acidente (artigo 86, de natureza indenizatória)

Sobre a importância de um benefício previdenciário que lide com o adoecimento nas relações de trabalho, é de extrema importância observar que os avanços tecnológicos sobre o processo do trabalho não trouxeram necessariamente ganhos de qualidade de vida para o trabalhador. Sobre isso, explica Luci Praun (2019, p. 202):

\footnotetext{
Ao longo das décadas de 1980 e 1990, muito se falou sobre a possibilidade efetiva de uma sociedade do tempo livre e suas potencialidades. Conforme essa perspectiva, tanto a degradação presente no interior das fábricas do século XIX com a embrutecedora separação entre o pensar e o executar, marcantes na "era fordista", estariam, a partir das últimas décadas do século XX, fadadas ao fim. Uma inversão estaria em curso. Ela traria o progressivo controle humano sobre o processo de trabalho.
}

Desta forma, embora os avanços tecnológicos tenham trazido ganhos para a sociedade como um todo, tal tese não se confirmou. Diante disso, o processo produtivo não impediu o adoecimento nas relações de trabalho, sendo na verdade um caminho inverso ao de uma sociedade do tempo livre. O desgaste na vida laboral que causa adoecimento entre os indivíduos segue ocorrendo diariamente, fator bastante preponderante na baixa qualidade de vida de muitas pessoas em todo mundo.

Nesta situação, doenças e acidentes são situações bastante recorrentes no mundo do trabalho, fazendo assim grande sentido que trabalhadores busquem amparo para este infortúnio. Conforme dados da Organização Internacional do Trabalho (OIT) divulgados em 2017, 2,3 milhões de pessoas no mundo morreram em decorrência de doenças e acidentes laborais, em um total de 300 milhões de acidentados e adoecidos (AGÊNCIA BRASIL, 2016).

Sobre este assunto, a OIT estabeleceu a Convenção 155 sobre Segurança e Saúde dos Trabalhadores, ratificada pelo Brasil em 1992. Logo, a proteção à saúde que sendo um direito de todos (com previsão no artigo $6^{\circ}$ da Constituição da República), também deve ser encarada como direito dos trabalhadores nos seus ambientes de trabalho. 
Portanto, há de se pensar sobre a proteção à saúde nas relações de trabalho, principalmente em tempos de uma pandemia de relevância mundial como a desencadeada pelo vírus “Covid-19”. Tendo em vista as diferentes posições sobre o tema, no próximo capítulo será conceituada a doença ocupacional.

\section{DOENÇA OCUPACIONAL: CONCEITUAÇÃO E ENTENDIMENTO JURISPRU- DENCIAL EM TEMPOS DE PANDEMIA.}

A Emenda Constitucional 103 de 2019, conhecida como "reforma da previdência", modificou o sistema previdenciário de maneira geral, criando novas regras e novas perspectivas para a previdência social brasileira. Sobre isso, importante ressaltar a mudança ocorrida no artigo 201, inciso I, da Constituição Federal:

Art. 201. A previdência social será organizada sob a forma do Regime Geral de Previdência Social, de caráter contributivo e de filiação obrigatória, observados critérios que preservem o equilíbrio financeiro e atuarial, e atenderá, na forma da lei, a:

I - cobertura dos eventos de doença, invalidez, morte e idade avançada; (Redação dada pela Emenda Constitucional nº 20, de 1998)

I - cobertura dos eventos de incapacidade temporária ou permanente para o trabalho e idade avançada; (Redação dada pela Emenda Constitucional nº 103, de 2019)

É interessante destacar que a redação do inciso I, conforme a Emenda Constitucional 20/1998 elencava as situações de; “doença, morte, incapacidade e idade avançada”. Já o inciso I redigido pela Emenda Constitucional 103/2019 frisa apenas a incapacidade (seja temporária ou permanente) e a idade avançada, excluindo desta forma as palavras "doença" e "morte".

Entende-se que este tipo de modificação deixa claro um viés de mudança de diretriz, isto é, de alteração na configuração da proteção social brasileira. Entretanto, independente disso, ainda existe proteção no ordenamento jurídico ao que tange eventos que resultam em doença do indivíduo ou morte de familiar segurado. É assegurada a proteção previdenciária de acordo com os institutos legais do auxílio doença e da pensão morte, conforme os artigos 59 e 74 da Lei 8213/91 respectivamente.

Embora a Lei Eloy Chaves de 1923 tenha trazido um marco formal para a previdência social brasileira, o Brasil já possuía normas esparsas e específicas. Por exemplo, o primeiro dispositivo legal a tratar de acidentes de trabalho é de 1919 (Decreto Legislativo n. 3.724) que equiparou acidente do trabalho com as doenças profissionais, o que ocorre até os dias de hoje (ZAINAGHI, 2018, p. 89).

Nos dias atuais, o artigo 20 da lei 8213/19 mantém esta equiparação, fazendo distinção entre o que é considerado "doença profissional" e "doença do trabalho". Zainaghi (2018, p. 89) explica que as doenças profissionais são chamadas de "típicas" por serem peculiares a determinada atividade profissional, já as doenças do trabalho são consideradas "atípicas", desencadeadas na forma com que o trabalho é prestado (sem vinculação com nenhuma profissão). 
No que tange especificamente ao auxílio doença, há previsão legal relativa ao amparo de trabalhadores que por ventura possam adoecer ou se acidentar em virtude da atividade profissional. Lazzari e Castro (2014, p. 551, 554 e 555) explicam que a doença ocupacional e o acidente de trabalho se deflagram em virtude da atividade laborativa do indivíduo. Os autores explicam como distinção entre o acidente e a doença o fato do acidente ocorrer por motivo de um evento súbito e violento, mas ambas situações são caracterizadas pela exterioridade da causa (motivo do ocorrido).

Gilberto e Bakhos (2016. 104) lembram que há por vezes bastante dificuldade na hora de se fazer avaliação com a pessoa incapacitada. Tal problema ocorre pelo fato de se enfocar mais no indivíduo em si, e menos no entorno (onde o segurado trabalha).

Na contramão desta (alegada) dificuldade, inúmeros estudos acadêmicos e estatísticas demonstram a ocorrência de determinados distúrbios específicos com maior frequência em determinadas categorias de profissionais do que na população em geral, comprovando a correlação entre o meio ambiente de trabalho e doenças mentais.

Carlos Henrique Bezerra Leite (2020, p. 582) ressalta que o afastamento do empregado por motivo de doença configura suspensão do contrato de trabalho, sendo devido auxílio-doença a partir do $16^{\circ}$ dia afastado. Diante disso, o trabalhador licenciado do serviço passa a ter direito ao benefício previdenciário e não mais ao salário pago pelo empregador.

Neste período de afastamento, há peculiaridades sobre o contrato de trabalho, pois na hipótese de doença ocupacional ou acidente de trabalho, cabe salientar que se trata de uma distinta modalidade de auxílio-doença. Isto é, há diferenciações quanto as responsabilidades empresariais caso seja o auxílio-doença acidentário e não auxílio-doença comum:

\section{Ementa.}

AGRAVO DE INSTRUMENTO EM RECURSO DE REVISTA. ESTABILIDADE PROVISÓRIA. AUXÍLIO-DOENÇA ACIDENTÁRIO. Consta do acórdão regional que a reclamante juntou comunicação de decisão do INSS concedendo auxílio-doença acidentário, sob o código 91, requerido em 16/10/2014 e com término na data de 26/12/2016, tendo o órgão previdenciário respondido ao ofício remetido pelo juiz confirmando a concessão desse benefício, no período de 7/09/2014 a 26/2/2016. Neste contexto, concluiu o Regional pelo direito da reclamante à estabilidade provisória, até 12 meses subsequentes à concessão do benefício, nos termos do artigo 118 da Lei 8213/1991, o que não foi observado pela reclamada, que a dispensou na data de 11/04/2016, o que resulta na obrigação de pagar os salários, férias, gratificações natalinas, FGTS e diferenças de verbas rescisórias do período remanescente, de 12/4/2016 a 27/2/2017, como decidido em primeira instância [...]. (BRASIL, 2020-a)

Assim, o auxílio-doença acidentário tem como característica a manutenção de obrigações trabalhistas como o pagamento do Fundo de Garantia por Tempo de Serviço (FGTS), conforme o artigo $15, \S 5^{\circ}$, da Lei 8.036/90. Além também, é direito do acidentado a estabilidade provisória em até 12 meses após a concessão do benefício (previsão do artigo 118 da Lei 8.213/91). 
Nos termos do artigo 26, II, da Lei 8.213/91, em caso de acidente laboral, doença profissional ou do trabalho, não há carência para o beneficiário do INSS obter a prestação previdenciária. Entretanto, em caso de doença comum, só é devido o benefício do auxílio-doença para os segurados que cumprirem a carência relativa a 12 meses de contribuição, conforme o artigo 25, I, da Lei 8213/91.

Ainda, em caso de afastamento do trabalhador acidentado, o tempo de contribuição para fins previdenciários segue contando normalmente (LAZZARI; CASTRO, 2018, p. 581). Essa distinção entre as duas modalidades se baseia no fato do auxílio acidentário ser de contribuição obrigatória (artigo 19-C do Decreto 3.048/99), enquanto o comum depende de contribuição intercalada.

Tendo em vista todas essas distinções, é importante destacar situações em que não se configura doença do trabalho, mas sim, doença comum. O artigo 20, $\S 1^{\circ}$ da Lei 8.213/91 elenca situações específicas em que não se deve considerar como doença do trabalho:
a) a doença degenerativa;
b) a inerente a grupo etário;
c) a que não produza incapacidade para o trabalho;
d) a doença endêmica adquirida por segurado habitante de região em que ela se desenvolva, salvo comprovação de que é resultante de exposição ou contato direto determinado pela natureza do trabalho.

Dentre essas quatro possibilidades, há que se refletir sobre a alínea "d" do referido artigo. Conforme o dispositivo legal, é exceção a referida regra casos de doença endêmica quando for comprovado o nexo da exposição ou contato direto em decorrência do trabalho, logo, tal situação merece ser vista pela ótica de acontecimentos recentes, como da pandemia decorrente do coronavírus.

Isto é, no ano de 2020 o mundo se deparou com uma grande crise sanitária e econômica causada pela Covid-19. Logo, se entendermos que uma endemia adquirida por um indivíduo exposto a doença em virtude do trabalho pode ser vista como doença ocupacional (comprovando o nexo em relação ao trabalho), não seria perfeitamente compreensível que em caso de pandemia (e pelo nome já é maior que uma endemia) deveria haver entendimento semelhante?

Por exemplo, algumas categorias profissionais devido ao tipo de trabalho, estão mais expostos ao contágio, como caixas de supermercado, empregadas domésticas, motoristas e entregadores (A Gazeta, 2020). Contudo, para se chegar ao entendimento de que a Covid-19 é uma doença com maior probabilidade de infecção em indivíduos que se encontram fora do ambiente domiciliar (como no ambiente laboral), é necessário entender as recentes definições sobre o tema.

Embora não especificamente sobre a Covid-19, mas ao que tange a responsabilização patronal por doença ocupacional ou acidente de trabalho, uma importante decisão foi proferida em março de 2020 por meio do Supremo Tribunal Federal (STF): 
PROTEÇÃO AOS DIREITOS SOCIAIS. POSSIBILIDADE DE RESPONSABILIZAÇÃO

OBJETIVA DO

EMPREGADOR POR DANOS DECORRENTES DE ACIDENTES DE TRABALHO. COMPATIBILIDADE DO ART. 7, XXVIII DA CONSTITUIÇÃO FEDERAL COM O ART. 927, PARÁGRAFO ÚNICO, DO CÓDIGO CIVIL. APLICABILIDADE PELA JUSTIÇA DO TRABALHO. (BRASIL, 2020-b)

Trata-se de um Recurso Extraordinário que buscou uniformizar a aplicabilidade da responsabilização patronal na Justiça do Trabalho. Diante disso, o Tribunal Superior do Trabalho (TST) demonstrou seguir os mesmos preceitos:

AGRAVO DE INSTRUMENTO EM RECURSO DE REVISTA INTERPOSTO PELA RECLAMADA. JULGAMENTO ANTERIOR PELA TURMA. DEVOLUÇÃO PARA O EXERCÍCIO DE EVENTUAL JUÍZO DE RETRATAÇÃO. RESPONSABILIDADE OBJETIVA. 1. Esta Turma negou provimento ao agravo de instrumento interposto pela reclamada, mantendo, por conseguinte, a decisão regional que concluiu pela responsabilidade objetiva da recorrente pelos danos sofridos. 2. Ora, no julgamento do RE ${ }^{\circ} 828040$, em sede de repercussão geral (Tema $n^{\circ}$ 932), o Supremo Tribunal Federal fixou a tese de que “o artigo 927, parágrafo único, do Código Civil é compatível com o artigo $7^{\circ}$, XXVIII, da Constituição Federal, sendo constitucional a responsabilização objetiva do empregador por danos decorrentes de acidentes de trabalho, nos casos especificados em lei, ou quando a atividade normalmente desenvolvida, por sua natureza, apresentar exposição habitual a risco especial, com potencialidade lesiva e implicar ao trabalhador ônus maior do que aos demais membros da coletividade ". 3. Constata-se, assim, que a presente controvérsia foi equacionada em harmonia com o aludido precedente de repercussão geral, haja vista que, embora não se trate de acidente de trabalho, a atividade desenvolvida nas dependências do banco postal apresenta, por sua natureza, exposição a risco, como na hipótese em análise, em que houve exposição a cinco assaltos no período de um ano. 4. Por conseguinte, mantida a decisão que negou provimento ao agravo de instrumento interposto pela reclamada [...] (BRASIL, 2020-c)

Sobre isso, importante salientar que muitas atividades foram modificadas na pandemia do "coronavírus", sendo algumas desenvolvidas de maneira remota e telepresencial e outras não (aumentando assim o risco de contágio para muitos trabalhadores). Nesta situação, há que se ater à responsabilidade objetiva do empregador, sendo os riscos da atividade empresarial assumidos por este (como preceitua o artigo $2^{\circ}$ da CLT).

De maneira coerente com esta premissa, o Ministério da Saúde ligado ao governo federal publicou em setembro de 2020 a Portaria de n. 2.309, incluindo a Covid-19 na lista de doenças ocupacionais. Porém, no dia seguinte o órgão que ministra a saúde revogou a medida por meio de outra Portaria (n. 2.345,) excluindo assim a Covid-19 do rol de doenças ocupacionais.

Tal problemática já tinha surgido no começo da pandemia no Brasil, conforme previsão do artigo 29 da Medida Provisória 927, instituída pelo Presidente da República no dia 22 de março de 2020. De acordo com o texto legal; “Os casos de contaminação pelo coronavírus (covid-19) não serão considerados ocupacionais, exceto mediante comprovação do nexo causal”. 
Embora o dispositivo legal tenha sido confrontado no Supremo Tribunal Federal por meio de sete ações que visavam à declaração da sua inconstitucionalidade (BRASIL, 2020-d), de fato, observa-se uma grande insegurança jurídica para o caso. Portanto, no próximo capítulo será feito uma análise sobre a possibilidade da doença decorrente da Covid-19 ser considerada doença ocupacional.

\section{COVID-19 COMO DOENÇA OCUPACIONAL: UMA ANÁLISE CRÍTICA.}

Sendo a pandemia desencadeada pelo vírus da Covid-19 uma peculiaridade que deveria agravar o nível de preocupação da sociedade em relação à proteção da saúde, seria de se imaginar que as medidas estatais seriam na diretriz de fortalecer cuidados neste sentido. Porém, a Medida Provisória 927 editada em março de 2020 trouxe flexibilização de direitos trabalhistas e também de fiscalização.

Embora a MP 927 tenha perdido eficácia em decorrência de não apreciação do Congresso Nacional (CONSULTOR JURÍDICO, 2020), antes disso, em abril (mês seguinte a sua edição) o STF foi invocado a se manifestar sobre a sua inconstitucionalidade. Embora o STF tenha mantido o teor do texto intacto, a Corte Suprema considerou dois artigos inconstitucionais, o artigo 29 sobre doença ocupacional e o 31 sobre a atuação de auditores fiscais do trabalho durante a pandemia:

\section{Art. 29. Os casos de contaminação pelo coronavírus (covid-19) não serão considerados} ocupacionais, exceto mediante comprovação do nexo causal.

Art. 31. Durante o período de cento e oitenta dias, contado da data de entrada em vigor desta Medida Provisória, os Auditores Fiscais do Trabalho do Ministério da Economia atuarão de maneira orientadora, exceto quanto às seguintes irregularidades:

I - falta de registro de empregado, a partir de denúncias;

II - situações de grave e iminente risco, somente para as irregularidades imediatamente relacionadas à configuração da situação;

III - ocorrência de acidente de trabalho fatal apurado por meio de procedimento fiscal de análise de acidente, somente para as irregularidades imediatamente relacionadas às causas do acidente; $\mathrm{e}$ IV - trabalho em condições análogas às de escravo ou trabalho infantil.

Logo, a decisão do STF se baseou na ofensa ao artigo $1^{\circ}$, IV da Constituição Federal, norma fundamental que expressa serem igualmente importantes a "livre iniciativa" e os "valores sociais do trabalho". Em contraponto ao preceito constitucional, o artigo 31 da MP 927 visava reduzir a fiscalização dos auditores fiscais (essenciais em período de calamidade pública), e na mesma linha, o artigo 29 desconsiderou o risco à saúde de muitos trabalhadores que tiveram exposição ao vírus em virtude do trabalho.

Ao que diz respeito a isonomia entre valores sociais do trabalho e livre iniciativa artigo $1^{\circ}$, IV, CF), Mauricio Godinho Delgado (2017, p. 61) faz a seguinte ponderação:

É inconstitucional, para o Texto Máximo, a antítese "o lucro ou as pessoas"; a livre iniciativa e o lucro constitucionalmente reconhecidos - e, nessa medida, protegidos - são aqueles que agreguem valor aos seres humanos, à convivência e aos valores da sociedade, à higidez do meio ambiente geral, inclusive o do trabalho. 
Infelizmente, medidas como estas demonstram um viés apenas de desproteger os trabalhadores, seja em flexibilizar a fiscalização (artigo 31), seja em minimizar os riscos do vírus (artigo 29 que desconsiderou ser caso de doença ocupacional). Sendo assim, mesmo que o Poder Judiciário tenha se manifestado de maneira contrária aos artigos citados, trata-se de uma situação peculiar e de grande insegurança jurídica (tendo em vista este tipo de medida).

Sobre a proteção à integridade física e psíquica do trabalhador de maneira geral, Felipe Gondim Brandão (2018, p. 111) afirma a importância das normas relativas à saúde, segurança e higiene no ambiente de trabalho; "Pretende-se não se deixar esquecer que a Carta Magna de 1988 definiu um referencial a ser alcançado, a saber o direito à redução aos riscos no ambiente de trabalho, capitulado no seu artigo $7^{\circ}$, inciso XXII".

Desta maneira, é de suma importância entender as peculiaridades relativas a pandemia da Covid-19. Isto é, em março de 2020 foi divulgado pelo Ministério da Saúde que 2.800 pessoas estavam contaminadas pelo vírus da Covid-19 (UOL, 2020). Diante de tal situação, o Ministério da Saúde publicou a Portaria n.356, com o intuito de estabelecer medidas para enfrentamento da pandemia em consonância com a Organização Mundial da Saúde - OMS (BRASIL, 2020-e). De acordo com a Lei 13.979/20, de iniciativa do Poder Executivo e apreciada pelo Congresso Nacional:

\footnotetext{
Art. $3^{\circ}$ : Para enfrentamento da emergência de saúde pública de importância internacional de que trata esta Lei, as autoridades poderão adotar, no âmbito de suas competências, entre outras, as seguintes medidas:

I - isolamento;

II - quarentena; [...]
}

Logo, diante de uma situação de calamidade pública onde foi estabelecido o isolamento social e a quarentena como forma de diminuir danos em uma crise sanitária, estar trabalhando significa pra muitas pessoas estar em contato com número elevado de pessoas (ocorrendo maior possibilidade de contaminação). Em uma situação assim, é de se destacar que embora a contaminação possa ser feita em ambiente diverso, o ambiente de trabalho é sim um lugar de risco.

Como já referido anteriormente, a responsabilização civil do empregador é objetiva em casos de acidente laboral (equiparado à doença ocupacional), entendimento que deve ser o mesmo no período da pandemia. Sobre este tipo de responsabilidade, Rui Stocco (2014, p. 1022) ressalta que para a responsabilização civil do empregador em nenhum momento importa a culpa ou o dolo, sendo então uma responsabilidade objetiva, salvo quando há previsão expressa em lei.

Com isso, afirma-se que o reconhecimento do vírus da Covid-19 como doença ocupacional estabelece maior segurança para toda sociedade, levando em conta a importância do trabalho no sustento das pessoas. Logo, havendo com a realização da atividade laboral maior risco aos trabalhadores (como no caso da pandemia), não é viável a adoção de medidas contrárias à proteção social. 
Embora seja possível a contaminação do vírus em diversas situações do cotidiano, a relação com o trabalho deve ser levada em consideração, principalmente em um período atípico. Gilberto e Bakhos (2016, p. 114) ressaltam que embora o adoecimento possa ter motivos multifatoriais, o ambiente de trabalho é prepondera como elemento propulsor deste tipo de moléstia.

Barbato $(2018$, p. 216) destaca que em caso de negativa de benefício previdenciário pela via administrativa, os indivíduos já estão em situação assimétrica caso venham a buscar seus direitos pela via judicial:

As demandas previdenciárias são movidas em face do INSS, ou seja, de um lado há o cidadão hipossuficiente e, de outro, como réu, uma autarquia Federal bem estruturada. Deste modo, enquanto a parte autora não detém sequer conhecimento de seus direitos, o Réu, diferentemente, possui todas as informações e documentos relativos à pretensão do autor.

Portanto, uma situação como essa, em que há diferentes entendimentos sobre a doença ocupacional, surge uma grande insegurança para todas as partes envolvidas, em especial o trabalhador que em caso de litígio previdenciário já estaria em situação desprivilegiada em relação ao INSS. Com isso, ressalta-se o entendimento de que o vírus da Covid-19 deve ser considerado como doença ocupacional, seja em virtude de uma maior segurança jurídica para as partes envolvidas, seja para garantir maior proteção aos trabalhadores.

\section{CONCLUSÃO}

Diante do que foi exposto, ressalta-se que situações excepcionais de crise sanitária e calamidade pública merecem um tratamento sério e responsável. Logo, não se pode esquecer que a saúde é um direito fundamental de todos os brasileiros, conforme o artigo $6^{\circ}$ da Constituição Federal de 1988.

Da mesma forma, a Constituição da República prevê no artigo $7^{\circ}$, XXII: "redução dos riscos inerentes ao trabalho, por meio de normas de saúde, higiene e segurança". Assim, este tipo de diretriz deve ser o caminho a se pautar em todos os momentos, em especial em um caso de pandemia, levando em conta o interesse público de toda sociedade.

Este trabalho não se ateve em discutir questões que não condizem com o objeto de estudo, como obrigatoriedade de isolamento social, quarentena e outras medidas utilizadas para contenção do vírus da Covid-19. Contudo, se discutiu a respeito do Poder Executivo federal ter tomado medidas que visavam desconsiderar o vírus da Covid-19 como caso de doença ocupacional. Trata-se de uma medida combatida pelo Poder Judiciário, pois a realidade fática pode comprovar a relação da contaminação com o ambiente de trabalho (como em casos que vários funcionários de um mesmo estabelecimento foram contaminados).

Portanto, conclui-se sobre a importância de se afirmar que o vírus da Covid-19 pode ser considerado como doença ocupacional, tendo em vista todas as peculiaridades sobre o tema. Sendo assim, 
acredita-se que algumas medidas adotadas pelo Poder Executivo contribuíram para uma insegurança jurídica, prejudicial para todas as partes envolvidas (em especial ao trabalhador).

\section{REFERÊNCIAS}

BARBATO, Adriana Riberto. Processo previdenciário - avanços e percalços. In: CÉSAR, Guillermo Rojas de Cerqueira. O direito previdenciário na visão dos defensores públicos federais. Belo Horizonte: Editora D’Plácido, 2019. p. 213-228.

BERGER, Adri. Acidentes de trabalho matam 2,3 milhões por ano mundo, diz OIT. Disponível em: https://bit.ly/3q6BQ7o. Acesso em: 16 nov. 2020. Acesso em: 16 nov. 2020.

BRANDÃO, Felipe Gondim. O direito à redução dos riscos no meio ambiente do trabalho: um compromisso constitucional. In: ROCHA, Cláudio Jannotti da; PORTO, Lorena Vasconcelos, BORSIO, Marcelo, ALVARENGA, Rúbia Zanotelli de (org). Proteção à saúde e segurança no trabalho. São Paulo: Ltr, 2018. p. 111-126.

BRASIL. Constituição Federal. Brasília, DF, 1988. Disponível em: https://bit.ly/3qh7grF. Acesso em 16 nov. 2020.

BRASIL. Decreto 3048 de 1999. Dispõe sobre o regulamento da Previdência Social. Disponível em: https://bit.ly/2XAOZJE. Acesso em: 16 nov. 2020.

BRASIL. Lei 8036 de 1990. Lei que dispõe sobre o Fundo de Garantia por Tempo de Serviço (FGTS). Disponível em: https://bit.ly/3i7uYUp. Acesso em: 16 nov. 2020.

BRASIL. Lei 8212 de 1991. Lei que dispõe sobre a Seguridade Social. Disponível em: https://bit.ly/ 3shox66. Acesso em: 16 nov. 2020.

BRASIL. Lei 8213 de 1991. Lei que dispõe sobre os benefícios da Previdência Social. Disponível em: https://bit.ly/38C29MN. Acesso em: 16 nov. 2020.

BRASIL. Medida Provisória 927, de março de 2020. Diário Oficial da República Federativa do Brasil. Disponível em: https://bit.ly/39sTQCn. Acesso em: 16 nov. 2020-d. 
BRASIL. Portaria 2.309. Ministério da Saúde. Gabinete do Ministro. Disponível em: https://bit.ly/ 3i4UsC1. Acesso em: 16 nov. 2020.

BRASIL. Portaria 2.345. Ministério da Saúde. Gabinete do Ministro. Disponível em: https://bit.ly/ 3i7VAVi. Acesso em: 16 nov. 2020.

BRASIL. Portaria 356. Ministério da Saúde. Gabinete do Ministro. Disponível em: https://bit.ly/ 3qcWEKt. Acesso em: 16 nov. 2020-e.

BRASIL. Supremo Tribunal Federal. Recurso Extraordinário 828040 (RE). Responsabilidade objetiva do empregador decorrente de acidente de trabalho. Recorrente: Protege S/A - Proteção e Transportes de Valores. Recorrido: Marcos da Costa Santos. Relator Alexandre de Moraes, Primeira Turma, 12/03/2020-b. Disponível em: https://bit.ly/3qgAvea. Acesso em: 16 nov. 2020.

BRASIL. Tribunal Superior do Trabalho. Agravo de Instrumento em Recurso de Revista 10267982.2016.5.010481 (AIRR). Agravante: GR Serviços e Alimentação Ltda. Agravada: Claudinéia Silveira Azevedo. Relatora Dora Maria da Costa, $8^{\circ}$ turma, 5/08/2020-a. Disponível em: https://bit. 1y/39sYcsW. Acesso em: 16 nov. 2020.

BRASIL. Tribunal Superior do Trabalho. Agravo de Instrumento em Recurso de Revista 94652.2016.5.09.0125. Agravante: João Aires Savaris. Agravada: Copel Distribuição S/A. Relatora Dora Maria da Costa, $8^{\circ}$ turma, 5/08/2020-c. Disponível em: https://bit.ly/3seS6Fk. Acesso em: 16 nov. 2020.

CASTRO, Carlos Alberto; LAZZARI, João Batista. Manual de Direito Previdenciário. 21 ed. Rio de Janeiro: Editora Forense, 2018.

DELGADO, Mauricio Godinho. Princípios constitucionais do trabalho e princípios de direito individual e coletivo do trabalho. 5. ed. São Paulo: LTr, 2017.

FAGNANI, Eduardo. Previdência: O debate desonesto: Subsídios para a ação social e parlamentar: pontos inaceitáveis da Reforma de Bolsonaro. São Paulo: Editora Contracorrente, 2019.

GILBERTO, Camila Marques; BAKHOS, Lilian Muniz. A caracterização de auxílios-doença acidentários por transtornos mentais após a criação do NTEP. Revista de Direitos Sociais, Seguridade e Previdência. Florianópolis, v.2, n.1, p. 100-117, jan./jun, 2016. 
GONÇALVES, Siumara. Os profissionais mais ameaçados pela infecção do coronavírus. Disponível: https://bit.ly/35AnTXH. Acesso em: 17 nov. 2020.

FRAIA, Francine de. As consequências da caducidade da Medida Provisória 927/2020. Disponível: https://bit.ly/3oJ33go. Acesso em: 16 nov. 2020.

KERTZMAN, Ivan. Curso prático de Direito Previdenciário. 17 ed. Salvador: Editora JusPodivm, 2019.

LEITE, Carlos Henrique Bezerra. Curso de direito do trabalho. 12 ed. São Paulo: Saraiva, 2020.

MARTINEZ, Wladimir Novaes. A Seguridade Social na Constituição Federal. 2 ed. São Paulo: LTr, 1992.

MARTINEZ, Wladimir Novaes. História da previdência social brasileira. In: MARTINEZ, Wladimir Novaes; BALERA, Wagner; MARTINS, Ives Gandra da Silva. História, custeio e constitucionalidade da previdência social. São Paulo: LTr, 2015.

ORGANIZAÇÃO INTERNACIONAL DO TRABALHO. Convenção 155, de 1981. Convenção sobre saúde e segurança dos trabalhadores. Disponível em: https://bit.ly/3oDEhhA. Acesso em: 16 nov. 2020.

PORTAL UOL. OMS diz que só isolamento controlará covid-19 e anuncia morte de crianças. Disponível: https://bit.ly/3sidkCb. Acesso em 16 jun. 2020.

PRAUN, Luci. Trabalho, adoecimento e descartabilidade humana. In: ANTUNES, Ricardo (org). Riqueza e miséria do trabalho no Brasil IV: trabalho digital, autogestão e expropriação da vida. São Paulo: Boitempo, 2019. p. 181-203.

STOCCO, Rui. Tratado de Responsabilidade Civil: Doutrina e Jurisprudência. 10. ed. São Paulo: Revista dos Tribunais, 2014.

ZAINAGHI, Domingos Salvio. A depressão no ambiente de trabalho. In: ROCHA, Cláudio Jannotti da; PORTO, Lorena Vasconcelos, BORSIO, Marcelo, ALVARENGA, Rúbia Zanotelli de (org). Proteção à saúde e segurança no trabalho. São Paulo: LTr, 2018. p. 87-91. 